\title{
COPA DO MUNDO FUTEBOL 2014 E JOGOS OLÍMPICOS RIO 2016 COMO POLÍTICAS PÚBLICAS DE ESTADO E DE GOVERNO: EQUÍVOCOS INEQUÍVOCOS
}

\author{
Recebido em: 03/03/2020 \\ Aprovado em: 18/08/2020 \\ Licença:@) (1) @ \\ Marco Aurélio Paganella ${ }^{1}$ \\ Sílvia Cristina Franco Amaral ${ }^{2}$ \\ Universidade Estadual de Campinas (UNICAMP) \\ Campinas - SP - Brasil
}

\begin{abstract}
RESUMO: Na Copa do Mundo Futebol 2014 e Olimpíadas Rio 2016 foram investidos 66 Bilhões de Reais, grande parte em estádios e parques esportivos: o sistema jurídico brasileiro permite estes gastos? O objetivo é cotejar disposições da ordem jurídica do país sobre esporte, saúde, educação e lazer, em face da opção pelos onerosos megaeventos esportivos. Metodologicamente, é um estudo analítico-comparativo correlacionando os gastos com estádios e parques olímpicos com os principais documentos sobre os referidos direitos sociais. Como resultados, não há compatibilidade entre o ordenamento jurídico e os gastos. O país investiu equivocadamente porque o sistema jurídico brasileiro prioriza a infraestrutura de base para a saúde, educação, esporte e lazer. Os atletas e medalhistas olímpicos merecem todo respeito, mas, pela imposição jurídica, megaeventos esportivos desta magnitude não deveriam ter sido realizados no Brasil.
\end{abstract}

PALAVRAS-CHAVE: Estado e Políticas Públicas. Direitos Sociais e Megaeventos Esportivos. Copa do Mundo 2014. JogosOlímpicos Rio 2016.

\section{SOCCER WORLD CUP AND RIO 2016 OLYMPIC GAMES AS PUBLIC POLICIES OF STATE AND GOVERNMENT: UNEQUIVOCAL MISTAKES}

ABSTRACT: In the 2014 Soccer World Cup and Rio 2016 Olympics 66 Billion Reais were invested, mostly in stadiums and sports parks: does the Brazilian legal system allow these expenses? The objective is to compare provisions of the country's judicial system on sports, health, education and leisure, in view of the option for the expensive sports mega-events. Methodologically, it is an analytical-comparative study correlating the expenditures with stadiums and Olympic parks with the main documents on the referred social rights. As a result, there is no compatibility between the judicial system and spending. The country invested wrongly because the Brazilian legal system prioritizes the basic infrastructure for health, education, sport and leisure. Olympic athletes and

\footnotetext{
${ }^{1}$ Doutorando em Educação Física - FEF/UNICAMP - Faculdade de Educação Física da Universidade Estadual de Campinas/SP. Membro do Grupo de Estudos e Pesquisa em Políticas Públicas e Lazer da UNICAMP. Professor do Curso de Educação Física do Centro Universitário Ítalo Brasileiro/SP.

2 Docente da Faculdade de Educação Física e do Programa de Pós-graduação em Educação Física da UNICAMP. Líder do Grupo de Estudos e Pesquisa em Políticas Públicas e Lazer da UNICAMP.
} 
medalists deserve all respect, but due to legal requirements, sports mega-events of this magnitude should not have been held in Brazil.

KEYWORDS: State and Public Policies. Social Rights and Sports Mega-Events. 2014 WorldCup. Rio 2016 Olympic Games.

\section{Introdução}

Tomando a perspectiva de Bracht (1997, p. 12), há: a) o esporte de alto rendimento ou espetáculo; b) o esporte enquanto atividade de lazer. No primeiro caso, o público praticante é, por óbvio, seleto, reduzido, restrito, mas, como espetáculo, seja com espectadores presentes no local das competições, seja via TV e outras mídias, é bastante amplo e há uma grande assistência.

No segundo, os praticantes podem e devem ser em grande número, democratizado, positivo para a sociedade, seja pela própria prática, seja por sua ligação com a educação, saúde, lazer propriamente dito e o exercício da própria cidadania, mas, em contrapartida, como se trata de algo difuso, pode-se dizer que, metaforicamente falando, pouca gente o vê e assiste.

Neste sentido, este estudo se justifica na medida em que os governantes apregoaram que estes megaeventos seriam fatores inequívocos para que o Brasil se tornasse um país desenvolvido. Segundo eles, os investimentos seriam feitos em infraestrutura geral, obras e intervenções, mobilidade urbana, metrôs, aeroportos, portos, saneamento, marketing e visibilidade ao País para trazer mais turistas e mostrar o quão avançado é o Brasil.

Levando-se em conta que os valores investidos somaram aproximadamente 66 Bilhões de Reais, sendo 26 Bilhões para a Copa 2014 (BRANDÃO, 2014) e 40 Bilhões para os Jogos Olímpicos Rio 2016 (FILIPO, 2017), a pergunta que se faz é se precisaria mesmo efetuar um enorme gasto em estádios de Futebol e parques esportivos destinados 
a estes megaeventos para que os investimentos nas áreas acima referidas se concretizassem? O sistema jurídico brasileiro permite essa escolha?

Esta pesquisa tem por objetivo cotejar as principais disposições normativas do sistema jurídico brasileiro sobre esporte, saúde, educação e lazer, em face da escolha feita pelos detentores do Poder pela realização no Brasil dos megaeventos esportivos Copa do Mundo Futebol 2014 e Jogos Olímpicos Rio 2016 enquanto política pública de Estado e de Governo deveras onerosa ao orçamento público.

Visa avaliar, portanto, se os documentos jurídicos, em comparação com os principais gastos dispendidos nestes megaeventos esportivos (dados obtidos no portal Transparência Brasil), dão guarida a esta opção feita pelos atores que detinham o poder público-político à época da candidatura, vitória e posterior realização.

Quanto à metodologia, trata-se de um estudo analítico-comparativo entre os principais documentos e disposições jurídico-normativas vigentes no País sobre esporte, saúde, educação e lazer, em relação a amostras de gastos com infraestrutura física/estádios de Futebol nas cidades em que não há clubes tradicionais, quando da Copa do Mundo de Futebol Brasil 2014.

E, também, em face dos gastos dispendidos com os parques olímpicos Barra, Deodoro, Copacabana, Maracanã, quando da realização dos Jogos Olímpicos Rio 2016, ambos os megaeventos esportivos notoriamente conhecidos.

Dados da população escolar brasileira, que poderia ser beneficiada com os recursos investidos nestes megaeventos, obtidos no censo escolar consignado em 2016 pelo INEP - Instituto Nacional de Estudos e Pesquisas Educacionais Anísio Teixeira (Inep), autarquia federal vinculada ao Ministério da Educação, e dados do IBGE Instituto Brasileiro de Geografia e Estatística, fundação pública ligada ao Ministério do Planejamento, Desenvolvimento e Gestão, que em 2019 passou a integrar o Ministério da 
Economia, amparam esta avaliação efetuada entre a dimensão normativa e o gasto dispendido à realização dos aludidos megaeventos esportivos em vez de investimentos mais amplos em setores essenciais à população em geral.

\section{Copa do Mundo Futebol 2014 e Jogos Olímpicos Rio 2016 como Políticas Públicas}

\section{de Estado e de Governo: Equívocos Inequívocos}

No dia 10 de dezembro de 1948, a Assembleia Geral das Nações Unidas (ONU, 1948, grifo nosso) adotou e proclamou a Declaração Universal dos Direitos Humanos (DUDH) que, inicialmente registra que:

\footnotetext{
- Considerando que os Estados-Membros se comprometeram a promover, em cooperação com as Nações Unidas, o respeito universal aos direitos e liberdades humanas fundamentais e a observância desses direitos e liberdades, [...]

Artigo XXIV - Todo ser humano tem direito a repouso e lazer, inclusive a limitação razoável das horas de trabalho e a férias remuneradas periódicas. [...] Artigo XXV - 1. Todo ser humano tem direito a um padrão de vida capaz de assegurar-lhe, e a sua família, saúde e bem-estar, inclusive alimentação, [...]

Artigo XXVI - 1. Todo ser humano tem direito à instrução. A instrução será gratuita, pelo menos nos graus elementares e fundamentais. A instrução elementar será obrigatória.

2. A instrução será orientada no sentido do pleno desenvolvimento da personalidade humana e do fortalecimento do respeito pelos direitos humanos e pelas liberdades fundamentais.
}

Antes mesmo da DUDH de 1948, em 1946, tenha-se presente que, a Constituição da Organização Mundial da Saúde de 1946 (OMS/WHO, 1946, grifo nosso) é clara quando diz que,

\footnotetext{
Os Estados Membros desta Constituição declaram, em conformidade com a Carta das Nações Unidas (1945), que os seguintes princípios são basilares para a felicidade dos povos, para as suas relações harmoniosas e para a sua segurança; (...)

A saúde é um estado de completo bem-estar físico, mental e social, e não consiste apenas na ausência de doença ou de enfermidade.
}

Em síntese, há 70 anos os Estados-Membros se comprometeram a promover, em cooperação com as Nações Unidas, o respeito universal aos direitos e liberdades humanas fundamentais e a sua inequívoca observância. Declararam que todo ser humano tem 
direito ao lazer, inclusive a limitação razoável das horas de trabalho e a férias remuneradas periódicas, e que todo ser humano tem direito a um padrão de vida capaz de assegurar-lhe, e a sua família, saúde e bem-estar.

E que todo ser humano tem direito à instrução elementar, obrigatória e gratuita, pelo menos nos graus elementares e fundamentais, a qual será orientada no sentido do pleno desenvolvimento da personalidade humana, até porque a saúde é um estado de completo bem-estar físico, mental e social.

Na mesma direção, a CF/88 não deixa dúvidas quanto à prioridade que o Estado brasileiro deve destinar à Saúde, à Educação, ao Bem-estar, à Cidadania, ao Lazer, e por extensão, ao Esporte em benefício da Sociedade:

Art. $1^{\circ}$ A República Federativa do Brasil, formada pela união indissolúvel dos Estados e Municípios e do Distrito Federal, constitui-se em Estado Democrático de Direito e tem como fundamentos: [...]

II -a cidadania

III - a dignidade da pessoa humana; [...]

Art. $3^{\circ}$ Constituem objetivos fundamentais da República Federativa do Brasil:

I - construir uma sociedade livre, justa e solidária;

II - garantir o desenvolvimento nacional;

III - erradicar a pobreza e a marginalização e reduzir as desigualdades sociais e regionais;

IV - promover o bem de todos, sem preconceitos de origem, raça, sexo, cor, idade e quaisquer outras formas de discriminação. [...]

Art. $4^{\circ}$ A República Federativa do Brasil rege-se nas suas relações internacionais pelos seguintes princípios: [...]

II - prevalência dos direitos humanos; [...] (BRASIL, 1988, grifo nosso).

Em suma, o Brasil, como Estado Democrático de Direito, tem como fundamentos a cidadania e a dignidade da pessoa humana, tem como objetivos fundamentais construir uma sociedade livre, justa e solidária, garantir o desenvolvimento nacional, erradicar a pobreza e a marginalização e reduzir as desigualdades sociais e regionais, promover o bem de todos, e rege-se, nas relações internacionais, entre outros, pela prevalência dos direitos humanos.

Nesta mesma direção, prossegue a $\mathrm{CF} / 88$ prescrevendo o que indubitavelmente deve ser feito, até porque, via de regra, Lei, em especial a Constitucional, em sua 
dimensão normativa, deve ser cumprida e, havendo discordância e questionamento, o deve ser feito perante o Judiciário:

\section{TÍTULO II - Dos Direitos e Garantias Fundamentais CAPÍTULO II - DOS DIREITOS SOCIAIS}

Art. $6^{\circ}$ São direitos sociais a educação, a saúde, a alimentação, o trabalho, a moradia, o transporte, o lazer, a segurança, a previdência social, a proteção à maternidade e à infância, a assistência aos desamparados, na forma desta Constituição. [...]

TÍTULO VIII - Da Ordem Social

Art. 193. A ordem social tem como base o primado do trabalho, e como objetivo o bem-estar e a justiça sociais.

Art. 194. A seguridade social compreende um conjunto integrado de ações de iniciativa dos Poderes Públicos e da sociedade, destinadas a assegurar os direitos relativos à saúde, [...].

Art. 196. A saúde é direito de todos e dever do Estado, garantido mediante políticas sociais e econômicas que visem à redução do risco de doença e de outros agravos e ao acesso universal e igualitário às ações e serviços para sua promoção, proteção e recuperação. [...]

Art. 198. As ações e serviços públicos de saúde integram uma rede regionalizada e hierarquizada e constituem um sistema único, organizado de acordo com as seguintes diretrizes:

I - descentralização, com direção única em cada esfera de governo;

II - atendimento integral, com prioridade para as atividades preventivas, sem prejuízo dos serviços assistenciais;

III - participação da comunidade. [...]

Art. 205. A educação, direito de todos e dever do Estado e da família, será promovida e incentivada com a colaboração da sociedade, visando ao pleno desenvolvimento da pessoa, seu preparo para o exercício da cidadania e sua qualificação para o trabalho. [...]

Art. 217. É dever do Estado fomentar práticas desportivas formais e nãoformais, como direito de cada um, observados: [...]

II - a destinação de recursos públicos para a promoção prioritária do desporto educacional e, em casos específicos, para a do desporto de alto rendimento; $[\ldots]$

$\S 3^{\circ} \mathrm{O}$ Poder Público incentivará o lazer, como forma de promoção social. [...]

Art. 227. É dever da família, da sociedade e do Estado assegurar à criança, ao adolescente e ao jovem, com absoluta prioridade, $o$ direito à vida, à saúde, à alimentação, à educação, ao lazer, à profissionalização, à cultura, à dignidade, ao respeito, à liberdade e à convivência familiar e comunitária, além de colocá-los a salvo de toda forma de negligência, discriminação, exploração, violência, crueldade e opressão. (BRASIL, 1988, grifo nosso).

Em resumo, são direitos sociais a educação, a saúde e o lazer, a ordem social tem

como objetivo o bem-estar, a seguridade social compreende um conjunto integrado de

ações destinadas a assegurar os direitos relativos à saúde, que é direito de todos e dever

do Estado, garantido mediante políticas sociais e econômicas que visem à redução do 
risco de doença e de outros agravos e ao acesso universal e igualitário às ações e serviços para sua promoção, proteção e recuperação.

Além disso, as ações e serviços públicos de saúde integram uma rede regionalizada e hierarquizada e constituem um sistema único (SUS), organizado de acordo com as diretrizes da descentralização, do atendimento integral, com prioridade para as atividades preventivas, e da participação da comunidade.

Por sua vez, a educação é um direito de todos e dever do Estado e da família, será promovida e incentivada com a colaboração da sociedade visando ao pleno desenvolvimento da pessoa, seu preparo para o exercício da cidadania e sua qualificação para o trabalho, bem como é dever do Estado fomentar práticas desportivas formais e nãoformais, como direito de cada um, observada a destinação de recursos públicos para a promoção prioritária do desporto educacional.

Lenza (2016) explica que os destinatários imediatos e mediatos destes direitos são os cidadãos, o Estado e os Governos e novamente os próprios cidadãos.

E isto significa dizer que, como determina o Art. 37, caput, da CF/1988 combinado com o Art. $2^{\circ} \mathrm{n}^{\circ}$ Lei 9.784/1999, a administração pública direta e indireta de qualquer dos Poderes da União, dos Estados, do Distrito Federal e dos Municípios, em todos os sentidos, inclusive e em especial, nas escolhas/decisões políticas, deverá observar os princípios de moralidade, publicidade, eficiência, finalidade, motivação, razoabilidade, proporcionalidade e interesse público. (BRASIL, 1988; BRASIL, 1999).

Na dimensão normativa infraconstitucional, a Lei nº 8.080/1990 implantou o SUS - Sistema Único de Saúde, a qual dispõe sobre as condições para a promoção, proteção e recuperação da saúde, a organização e o funcionamento dos serviços correspondentes entre outras providências:

\section{DISPOSIÇÃO PRELIMINAR}


Art. $1^{\circ}$ Esta lei regula, em todo o território nacional, as ações e serviços de saúde, executados isolada ou conjuntamente, em caráter permanente ou eventual, por pessoas naturais ou jurídicas de direito Público ou privado.

\section{TÍTULO I - DAS DISPOSIÇÕES GERAIS}

Art. $2^{\circ}$ A saúde é um direito fundamental do ser humano, devendo o Estado prover as condições indispensáveis ao seu pleno exercício.

$\S 1^{\circ} \mathrm{O}$ dever do Estado de garantir a saúde consiste na formulação e execução de políticas econômicas e sociais que visem à redução de riscos de doenças e de outros agravos e no estabelecimento de condições que assegurem acesso universal e igualitário às ações e aos serviços para a sua promoção, proteção e recuperação.

$\S 2^{\circ} \mathrm{O}$ dever do Estado não exclui o das pessoas, da família, das empresas e da sociedade.

Art. $3^{\circ}$ Os níveis de saúde expressam a organização social e econômica do País, tendo a saúde como determinantes e condicionantes, entre outros, a alimentação, a moradia, o saneamento básico, o meio ambiente, o trabalho, a renda, a educação, a atividade física, o transporte, o lazer e o acesso aos bens e serviços essenciais. (Redação dada pela Lei n 12.864 , de 2013)

Parágrafo único. Dizem respeito também à saúde as ações que, por força do disposto no artigo anterior, se destinam a garantir às pessoas è coletividade condições de bem-estar físico, mental e social. (BRASIL, 1990, grifo nosso).

Isto quer dizer que as ações e serviços de saúde devem ser executados, isolada ou conjuntamente, em caráter permanente ou eventual, por pessoas naturais ou jurídicas de direito Público ou privado, eis que a saúde é um direito fundamental do ser humano.

Deve o Estado, portanto, prover as condições indispensáveis ao seu pleno exercício, em especial, na formulação e execução de políticas econômicas e sociais que visem à redução de riscos de doenças e no estabelecimento de condições que assegurem acesso universal e igualitário às ações e aos serviços para a sua promoção.

Até porque, como apregoa a Lei do SUS, os níveis de saúde expressam a organização social e econômica do País, tendo a saúde como determinantes e condicionantes a educação, a prática corporal e o lazer e o acesso aos bens e serviços essenciais, de modo que também dizem respeito à saúde as ações que se destinam a garantir às pessoas e à coletividade condições de bem-estar físico, mental e social.

As pessoas naturais ou jurídicas de direito público ou privado são as que o Art. 18 da CF/1988 combinado com o Art. 41, 42 e 44, do Código Civil brasileiro (CC/02), determinam: 
Art. 18. A organização político-administrativa da República Federativa do Brasil compreende a União, os Estados, o Distrito Federal e os Municípios, todos autônomos, nos termos desta Constituição.

Art. 41. São pessoas jurídicas de direito público interno:

I - a União;

II - os Estados, o Distrito Federal e os Territórios;

III - os Municípios;

IV - as autarquias, inclusive as associações públicas;

$\mathrm{V}$ - as demais entidades de caráter público criadas por lei.

Art. 42. São pessoas jurídicas de direito público externo os Estados estrangeiros e todas as pessoas que forem regidas pelo direito internacional público. [...]

Art. 44. São pessoas jurídicas de direito privado:

I - as associações;

II - as sociedades;

III - as fundações.

IV - as organizações religiosas;

V - os partidos políticos.

VI - as empresas individuais de responsabilidade limitada. (BRASIL, 1988; BRASIL, 2002).

No âmbito da dimensão normativa infraconstitucional, a Lei nº 9.394/1996 (a LDB), que estabelece as diretrizes e bases da educação nacional, determina como o Estado deve agir e atuar no que diz com as políticas públicas em favor da saúde, do lazer e da própria educação, com nítida orientação para a autonomia da pessoa no decorrer da sua vida pós-escola, em especial porque ressalta e valoriza a presença e a atuação dos Professores e Educadores, inclusive os de Educação Física:

TÍTULO I - Da Educação

Art. $1^{\circ} \mathrm{A}$ educação abrange os processos formativos que se desenvolvem na vida familiar, na convivência humana, no trabalho, nas instituições de ensino e pesquisa, nos movimentos sociais e organizações da sociedade civil e nas manifestações culturais.

$\S 1^{\circ}$ Esta Lei disciplina a educação escolar, que se desenvolve, predominantemente, por meio do ensino, em instituições próprias.

$\S 2^{\circ} \mathrm{A}$ educação escolar deverá vincular-se ao mundo do trabalho e à prática social.

TÍTULO II - Dos Princípios e Fins da Educação Nacional

Art. $2^{\circ} \mathbf{A}$ educação, dever da família e do Estado, inspirada nos princípios de liberdade e nos ideais de solidariedade humana, tem por finalidade o pleno desenvolvimento do educando, seu preparo para o exercício da cidadania e sua qualificação para o trabalho.

Art. $3^{\circ} \mathrm{O}$ ensino será ministrado com base nos seguintes princípios: [...]

II - liberdade de aprender, ensinar, pesquisar e divulgar a cultura, o pensamento, a arte e o saber; [...]

VII - valorização do profissional da educação escolar; [...]

IX - garantia de padrão de qualidade;

$X$ - valorização da experiência extra-escolar;

XI - vinculação entre a educação escolar, o trabalho e as práticas sociais. [...] 
Art. 26. Os currículos da educação infantil, do ensino fundamental e do ensino médio devem ter base nacional comum, a ser complementada, em cada sistema de ensino e em cada estabelecimento escolar, por uma parte diversificada, exigida pelas características regionais e locais da sociedade, da cultura, da economia e dos educandos. [...]

$\S 3^{\circ} \mathbf{A}$ educação física, integrada à proposta pedagógica da escola, é componente curricular obrigatório da educação básica, [...] (BRASIL, 1996, grifo nosso).

Em resumo, a educação abrange os processos formativos que se desenvolvem na vida familiar, na convivência humana, no trabalho, nas instituições de ensino e pesquisa, nos movimentos sociais e organizações da sociedade civil e nas manifestações culturais.

Tem por finalidade o pleno desenvolvimento do educando, seu preparo para o exercício da cidadania, sendo que o ensino será ministrado com base nos princípios da liberdade de aprender, ensinar, pesquisar e divulgar a cultura, o pensamento, a arte e o saber, da valorização do profissional da educação escolar, da garantia de padrão de qualidade, da valorização da experiência extraescolar e da vinculação entre a educação escolar, o trabalho e as práticas sociais.

Percebe-se que os currículos da educação infantil, do ensino fundamental e do médio devem ter base nacional comum, a ser complementada, em cada sistema de ensino e em cada estabelecimento escolar, por uma parte diversificada, exigida pelas características regionais e locais da sociedade, da cultura, da economia e dos educandos.

É claro, também, que a Educação Física, integrada à proposta pedagógica da escola, é um componente curricular obrigatório da educação básica.

Desta forma, seja na Escola, seja fora dela em instituições correlatas, no que diz com a educação, a saúde, as práticas corporais nos termos da Política Nacional de Promoção da Saúde (PNPS), o esporte e o lazer, é certo que a Educação Física e seus respectivos Professores são, indiscutivelmente, relevantes a toda sociedade e para o próprio exercício da cidadania da pessoa humana (BRASIL, 2014).

A Lei $n^{\circ} 9.615 / 1998$, que institui normas gerais sobre desporto entre outras providências, segue na linha retro apregoada: 


\section{CAPÍTULO I - DISPOSIÇÕES INICIAIS}

Art. $1^{\circ} \mathrm{O}$ desporto brasileiro abrange práticas formais e não-formais e obedece às normas gerais desta Lei, inspirado nos fundamentos constitucionais do Estado Democrático de Direito. [...]

$\S 2^{\circ}$ A prática desportiva não-formal é caracterizada pela liberdade lúdica de seus Praticantes. [...]

CAPÍTULO II - DOS PRINCÍPIOS FUNDAMENTAIS

Art. $2^{\circ} \mathrm{O}$ desporto, como direito individual, tem como base os princípios: [...]

III - da democratização, garantido em condições de acesso às atividades desportivas sem quaisquer distinções ou formas de discriminação;

IV - da liberdade, expresso pela livre prática do desporto, de acordo com a capacidade e interesse de cada um, associando-se ou não a entidade do setor; $\mathrm{V}$ - do direito social, caracterizado pelo dever do Estado em fomentar as práticas desportivas formais e não-formais; [...]

VIII - da educação, voltado para o desenvolvimento integral do homem como ser autônomo e participante, e fomentado por meio da prioridade dos recursos públicos ao desporto educacional;

IX - da qualidade, assegurado pela valorização dos resultados desportivos, educativos e dos relacionados à cidadania e ao desenvolvimento físico e moral; [...]

CAPÍTULO III - DA NATUREZA E DAS FINALIDADES DO DESPORTO Art. $3^{\circ} \mathrm{O}$ desporto pode ser reconhecido em qualquer das seguintes manifestações:

I - desporto educacional, praticado nos sistemas de ensino e em formas assistemáticas de educação, evitando-se a seletividade, a hipercompetitividade de seus praticantes, com a finalidade de alcançar o desenvolvimento integral do indivíduo e a sua formação para o exercício da cidadania e a prática do lazer;

II - desporto de participação, de modo voluntário, compreendendo as modalidades desportivas praticadas com a finalidade de contribuir para a integração dos praticantes na plenitude da vida social, na promoção da saúde e educação e na preservação do meio ambiente;

III - desporto de rendimento, praticado segundo normas gerais desta Lei e regras de prática desportiva, nacionais e internacionais, com a finalidade de obter resultados e integrar pessoas e comunidades do País e estas com as de outras nações.

IV - desporto de formação, caracterizado pelo fomento e aquisição inicial dos conhecimentos desportivos que garantam competência técnica na intervenção desportiva, com o objetivo de promover o aperfeiçoamento qualitativo e quantitativo da prática desportiva em termos recreativos, competitivos ou de alta competição. (BRASIL, 1998, grifo nosso).

O desporto brasileiro, pois, abrange práticas formais e não-formais e é inspirado

nos fundamentos constitucionais do Estado Democrático de Direito, bem como a prática

desportiva não-formal é caracterizada pela liberdade lúdica de seus Praticantes.

Como direito individual, o esporte tem como base o princípio da democratização

e liberdade de prática conforme a capacidade e interesse de cada um. 
E, como direito social, caracteriza-se pelo dever do Estado em fomentar a educação às práticas desportivas formais e não-formais voltadas para o desenvolvimento integral do ser humano como ser autônomo e participante.

Para tanto, deve ser fomentado por meio da prioridade dos recursos públicos ao esporte educacional, assegurando, assim, a valorização dos resultados educativos relacionados à cidadania e ao desenvolvimento físico e moral.

O esporte, portanto, com base nesta Lei $\mathrm{n}^{\circ}$ 9.615/1998, deve ser reconhecido por meio de quatro manifestações, quais sejam, o já mencionado esporte educacional, praticado nos sistemas de ensino e em formas assistemáticas de educação, evitando-se a seletividade, a hipercompetitividade de seus praticantes, com o fim de alcançar o desenvolvimento integral do indivíduo e a sua formação para o exercício da cidadania e a prática do lazer.

O esporte de participação, praticado com a finalidade de contribuir para a integração dos praticantes na plenitude da vida social, na promoção da saúde e educação e na preservação do meio ambiente.

O esporte de rendimento, com a finalidade, sobretudo, de integrar pessoas e comunidades do País e estas com as de outras nações, o que talvez seja, pelo menos até agora, uma das poucas normas jurídicas estudadas que em tese subsidiariam a escolha pelos megaeventos, eis que, todas as outras convergem no sentido contrário.

E o esporte de formação, caracterizado pelo fomento e aquisição inicial dos conhecimentos esportivos com o objetivo de promover o aperfeiçoamento qualitativo e quantitativo da prática esportiva em termos recreativos.

Após esta análise do conteúdo jurídico, resta corroborado, portanto, que todo o sistema orienta o Estado brasileiro a priorizar a população em geral, de modo que o investimento deve ser, por força de lei constitucional, infraconstitucional e até mesmo por 
tratados internacionais, em favor do povo brasileiro em geral, e não para um grupo seleto, que merece respeito, consideração e atenção, mas, não como uma prioridade a se sobrepor à população brasileira.

Em linhas gerais, como explicam Frey (2000), e Muller e Surel (2000; 2002), tratam-se, as políticas públicas, de uma resposta do Estado às necessidades da sociedade que, por meio da formulação, elaboração, desenvolvimento, implantação, execução e posterior avaliação dos resultados das ações, programas e políticas implementadas, objetivam o bem-estar geral de todos numa ou em mais de uma área, sobretudo se já há Lei constitucional assim preestabelecendo.

Neste sentido, todos estes projetos, ações e programas, precisam ser estruturados de modo funcional e sequencial a fim de tornar possível a produção, organização, implementação e execução do projeto.

E isso ocorre com base no chamado ciclo das políticas públicas, que tem como fases, em síntese, 1) Identificação do problema público, 2) inclusão na agenda pública, 3) Possíveis soluções, 4) Formulação de políticas públicas, 5) Tomada de decisão, 6) Planejamento da execução, 7) Implementação da política pública, 8) Monitoramento, 9) Avaliação, 10) Manutenção e/ou início de um novo ciclo. (FREY, 2000; MULLER e SUREL, 2000; 2002).

Em cidades como Manaus/AM e Cuiabá/MT, com pouca tradição para o Futebol no âmbito nacional a justificar a construção de estádios com dinheiro público, para a Copa de 2014 foram construídos estádios colossais, grandiosos e caríssimos, inclusive para a sua manutenção, mas, com pouca utilidade para a população, sobretudo a escolar. (BRASIL, 2011a). 
Apenas como exemplo, à época foram quase 5 bilhões de Reais com os estádios nestas cidades, dinheiro este que seria bem mais útil à sociedade se aplicado nas escolas e em prol da população. (BRASIL, 2011a).

Mesmo que se argumente que, como se trata de empréstimos oriundos do BNDES - Banco Nacional do Desenvolvimento Econômico e Social (BRASIL, 1971), eles serão pagos, ainda assim tal assertiva não se sustenta.

É que, como é público e notório, o BNDES subsidia todo o investimento com recursos do Tesouro, haja vista que capta a juros SELIC - Sistema Especial de Liquidação e Custódia, e empresta a juros TJLP - Taxa de Juros de Longo Prazo, registrando que esta TJLP só vale até o final dos contratos em vigor porque a Lei $n^{\circ} 13.483 / 2017$ instituiu a TLP - Taxa de Longo Prazo para os novos contratos a partir de $1^{\circ}$ janeiro 2018 (BRASIL, 1964; BRASIL, 2017).

Como estes juros TJLP/TLP são menores que a SELIC, na maioria das vezes, por óbvio, não há equilíbrio nas contas, mesmo que se diga que o subsídio se justifica porque necessário ao investimento e, por extensão, ao desenvolvimento do País.

Para os Jogos Olímpicos Rio 2016 se aplica o mesmo raciocínio, qual seja, ao desativar o autódromo Nelson Piquet em Jacarepaguá e construir uma parte dos locais de provas, também foram gastos bilhões de Reais. (BRASIL, 2011b).

E, após o final dos Jogos Rio 2016, que duraram apenas 15 dias, não há mais autódromo, o parque olímpico está abandonado, vai uma fortuna para mantê-los, pouca gente o utiliza e, certamente, num lugar com governantes comprometidos com o cidadão, todo este dinheiro seria investido no bem-estar da população. (BRASIL, 2011b).

Da avaliação dos gastos nos Jogos Rio 2016, percebe-se também que foram gastos bilhões de Reais nestes jogos, dinheiro este que seria bem mais útil à sociedade se aplicado nas escolas e em prol da população. (BRASIL, 2011b). 
Com base no censo escolar 2016, são quase 40 milhões de estudantes, equivalente a praticamente um quinto da população brasileira, de mais de 205 milhões de habitantes, que em muitos casos, sequer há uma quadra poliesportiva na Escola, ou, se há, está em péssima condição, não só no aspecto físico, mas, também, no que diz com a vulnerabilidade do tráfico de drogas e outras mazelas que todos sabem que fazem parte do dia a dia. (INEP, 2016; IBGE, 2017).

Como escopo aqui não é avaliar minuciosamente todos os gastos nestes megaeventos esportivos realizados no Brasil, mas, sim, analisar se há consonância entre o que prescreve a legislação constitucional e infraconstitucional e a escolha política que foi feita pelo Estado e pelo Governo em favor destes megaeventos esportivos, é possível asseverar que há uma inequívoca dissonância.

Nesta sintonia, mesmo que se levasse em consideração o Segundo Tempo enquanto política pública à democratizar o acesso à prática e à cultura do esporte de forma a promover o desenvolvimento integral de crianças, adolescentes e jovens, como fator de formação da cidadania e melhoria da qualidade de vida, prioritariamente em áreas de vulnerabilidade social, não era necessário estes megaeventos com esta magnitude de gastos para que houvesse esse Segundo Tempo. (BRASIL, 2011c).

Bastava, na verdade, que esse Segundo Tempo fosse a preparação, o aquecimento, o Primeiro Tempo, o intervalo, o próprio Segundo Tempo, o pós-jogo, enfim, não precisava de megaeventos para impulsionar essa democratização.

Esses megaeventos não são necessários para investir e organizar a infraestrutura, obras e intervenções, mobilidade urbana, metrôs, aeroportos, portos, saneamento básico, educação, saúde, lazer, para dar visibilidade ao País, para trazer mais turistas estrangeiros, enfim, para toda e qualquer melhoria. 
É só ver o exemplo da Copa do Mundo de Futebol de 2006 na Alemanha, onde a infraestrutura toda já estava montada.

Mesmo no caso dos Jogos Olímpicos no Japão em 2020, onde a infraestrutura geral praticamente já está pronta, ainda assim há movimentos que se opõem em função dos excessivos gastos/dispêndios.

O Brasil é um País num estágio de desenvolvimento e de infraestrutura muito aquém do necessário, o que não permitiria investir nestes megaeventos esportivos sem prejuízo às suas respectivas populações.

Os megaeventos esportivos no Brasil deveriam ser a consequência, o corolário, o resultado de um País desenvolvido e de políticas públicas pautadas pelo que diz a legislação brasileira e o que diz o próprio bom senso e inteligência.

E não um pretenso fator essencial e elementar a dar um impulso para que fosse feito aquilo que deve ser feito pelo Estado e pelo Governo em prol de toda a população, inclusive e em especial, a escolar com mais de 40 milhões de alunos.

Os megaeventos esportivos Copa do Mundo 2014 e Olimpíada Rio 2016 foram grandes equívocos porque não são necessidades da sociedade, não são problemas públicos a ensejar uma ampla mobilização do Estado e dos Governos como o são, por exemplo, inundações oriundas de sabidas e conhecidas chuvas torrenciais em muitas regiões do Brasil.

Trata-se, portanto, de algo dissociado da base jurídico-institucional demonstrada, o que significa dizer que houve um grande equívoco em investir uma enorme quantia de recursos públicos em estádios de Futebol e parques es portivos para megaeventos, dinheiro este que certamente seria melhor investido, por exemplo, nas escolas públicas. 


\section{Considerações Finais}

Como resultados da pesquisa, pode-se afirmar que não há compatibilidade entre o que diz o ordenamento jurídico em favor da saúde, educação, esporte e lazer e a realização dos megaeventos esportivos Copa do Mundo de Futebol em 2014 e os Jogos Olímpicos Rio 2016.

O Estado e o Governo brasileiro dispenderam o dinheiro do povo brasileiro de modo equivocado, dado que deveriam ter feito diretamente em favor da população, em especial a escolar, sobretudo porque, normalmente, é assim que governos comprometidos com os seus deveriam atuar.

Ainda mais levando-se em conta que quem estava no comando e no exercício democrático do Poder à época da escolha do Brasil para estes megaeventos era um Governo que aludia que seu compromisso era para com a população mais necessitada do Brasil.

Resta inequívoco que, como políticas públicas para dar visibilidade, trazer mais turistas estrangeiros, implantar e construir uma infraestrutura digna, obras e intervenções, mobilidade urbana apropriada, metrôs, aeroportos, portos, entre outras melhorias, inclusive o Programa Segundo Tempo de inclusão e democratização esportiva, foi uma escolha inadequada do Estado e do governo brasileiro.

O Brasil não poderia ter megaeventos esportivos como pressuposto para que então fossem feitos investimentos em áreas essenciais, ou seja, o Brasil perdeu duplamente, seja porque desperdiçou tempo e recursos que poderiam ter sido investidos em áreas elementares, seja porque estas continuam precárias e sofríveis.

E isto sem contar os valores desviados pela hedionda corrupção que inclusive levou alguns daqueles detentores do Poder a várias condenações no judiciário, como é o caso do ex-governador do Rio de Janeiro Sergio Cabral. 
Os atores políticos e servidores públicos se equivocaram sobremaneira na escolha destes megaeventos esportivos como fator de fomento de desenvolvimento do País, ou, ainda, pode-se dizer que optaram propositadamente por estes gastos para poder usufruir da fama oriunda do suado dinheiro público e a eles alheio, em nítida falta de observância ao que preconiza a dimensão normativa brasileira.

A formulação de políticas públicas de saúde, educação, esporte e lazer com amplo acesso a todos, inclusive no âmbito escolar, é que deveria ter sido a prioridade para a democratização, autonomia, estado de bem-estar físico, mental, social e cultural do cidadão, algo que certamente os megaeventos esportivos não trouxeram.

A saúde física, mental, emocional, social, espiritual, familiar, política, cultural, ambiental, digital, financeira e a educação para a autonomia e para o pleno exercício da cidadania, esporte e lazer são muito mais importantes do que fazer marketing perante outrem sem infraestrutura geral adequada, algo que os megaeventos certamente não propiciaram aos brasileiros.

O desporto educacional, o desporto de participação e o desporto de formação devem ser fomentados em harmonia com o desporto de rendimento, sendo este o ápice da estrutura, o topo da pirâmide, e não a base tal como a escolha pelos megaeventos preconizou.

Até porque, quanto às opções e oportunidades de trabalho aos Professores de Educação Física e profissionais de áreas correlatas, naqueles três primeiros há muito mais do que neste último.

Com todo o respeito ao Esporte de alto rendimento e/ou espetáculo, que devem ser fomentados no seu devido tempo, lugar e circunstâncias, aos futebolistas, esportistas de alto nível e medalhistas olímpicos, que devem receber o carinho, estima, consideração 
e o respeito de todos, conclui-se que os megaeventos não deveriam ter sido realizados no Brasil.

Pela imposição jurídico-constitucional demonstrada, o que o Estado e os Governos deveriam ter feito era ter investido, organizado e priorizado a infraestrutura de base para a saúde, educação, esporte e lazer, para depois pensar em futuro bastante longínquo em sediar megaeventos esportivos desta magnitude.

\section{REFERÊNCIAS}

BRACHT, Valter. Sociologia crítica do esporte: uma introdução. Vitória/ES: UFES/ CEFD - Centro de Educação Física e Desportos, 1997.

BRANDÃO, Marcelo. TCU contabiliza R\$ 25,5 bilhões de gastos com a Copa do Mundo. Disponível em: http://agenciabrasil.ebc.com.br/geral/noticia/2014-12/tcucontabiliza-r-255-bilhoes-de-gastos-com-copa-do-mundo. Acesso em: 13 abr. 2018.

BRASIL. Constituição da República Federativa do Brasil de 1988. Diário Oficial da União, Brasília, D.O.U. 191-A DE 05/10/1988, p. 1.

Lei ${ }^{\circ} 4.595$, de 31 de dezembro de 1964. Dispõe sobre a Política e as Instituições Monetárias, Bancárias e Creditícias, Cria o Conselho Monetário Nacional e dá outras providências. Diário Oficial da União, Brasília, D.O. de 31/12/1964, p. 12.081(Suplemento). Disponível em: http://www.bcb.gov.br/pre/portalCidadao/bcb/bcFaz.asp?idpai=LAIINSTITUCIONA/ https://www.bcb.gov.br/pt-br/\#!/n/CMN/

http://www.bcb.gov.br/htms/selic/selicrtaxareg.asp?idpai=SELICTAXA/

http://www.bcb.gov.br/htms/selic/conceito_taxaselic.asp/ http://www.bcb.gov.br/ptbr/\#!/c/GLOSSARIO/

http://www.bndes.gov.br/wps/portal/site/home/financiamento/guia/custosfinanceiros/taxa-de-juros-de-longo-prazo-tjlp/. Acesso em : 31jul. 2017.

Lei $\mathrm{n}^{\mathrm{o}}$ 5.662, de 21 de junho de 1971. Enquadra o Banco Nacional do Desenvolvimento Econômico (BNDE) na categoria de empresa pública, e dá outras providências. Diário Oficial da União, Brasília, DOFC DE 21/06/1971, p. 4.697.

Lei $\mathrm{n}^{\circ}$ 8.080, de 19 de setembro de 1990. Dispõe sobre as condições para a promoção, proteção e recuperação da saúde, a organização e o funcionamento dos serviços correspondentes e dá outras providências. Diário Oficial da União, Brasília, DOFC de 20/09/1990, p. 18.055.

Lei $\mathrm{n}^{\circ}$ 9.394, de 23 de dezembro de 1996. Estabelece as diretrizes e bases da educação nacional. Diário Oficial da União, Brasília, D.O. de 23/12/1996, p. 27.833. 
BRASIL. Lei no 9.615, de 24 de março de 1998. Institui normas gerais sobre desporto e dá outras providências. Diário Oficial da União, Brasília, D.O. de 25/03/1998, p. 1.

Lei $\mathrm{n}^{\circ}$ 9.784, de 29 de janeiro de 1999. Regula o processo administrativo no âmbito da administração pública federal. Diário Oficial da União, Brasília, D.O. de 01/02/1999, p. 1.

Lei $\mathrm{n}^{\circ} 10.406$, de 10 de janeiro de 2002. Institui o Código Civil. Diário Oficial da União, Brasília, D.O.U. de 11/01/2002, p. 1.

Lei $\mathrm{n}^{\mathrm{o}}$ 12.527, de 18 de novembro de 2011.Regula o acesso a informações previsto no Inciso XXXIII do Art. $5^{\circ}$, no Inciso II do $\S 3^{\circ}$ do Art. 37 e no $\S 2^{\circ}$ do Art. 216 da Constituição Federal; altera a Lei $\mathrm{n}^{\circ}$ 8.112, de 11 de dezembro de 1990; revoga a Lei $\mathrm{n}^{\circ}$ 11.111, de 5 de maio de 2005, e dispositivos da Lei $\mathrm{n}^{\circ} 8.159$, de 8 de janeiro de 1991; e dá outras providências.2011a. Diário Oficial da União, Brasília, D.O.U. de 18/11/2011, p. 1 (Edição Extra). Disponível em: http://www.portaltransparencia.gov.br/copa2014/financiamentos/detalhe.seam?tema=6 \&assunto=tema. Acesso em: 30 jul. 2017.

Lei $\mathrm{n}^{\circ} 12.527$, de 18 de novembro de 2011. Regula o acesso a informações previsto no Inciso XXXIII do Art. $5^{\circ}$, no Inciso II do $\S 3^{\circ}$ do Art. 37 e no $\S 2^{\circ}$ do Art. 216 da Constituição Federal; altera a Lei $\mathrm{n}^{\circ}$ 8.112, de 11 de dezembro de 1990; revoga a Lei $\mathrm{n}^{\circ}$ 11.111, de 5 de maio de 2005, e dispositivos da Lei ${ }^{\circ} 8.159$, de 8 de janeiro de 1991; e dá outras providências.2011b. Diário Oficial da União, Brasília, D.O.U. de 18/11/2011, p. 1 (Edição Extra). Disponível em: http://www.portaldatransparencia.gov.br/rio2016/origem-dos-dados/. Acesso em: 30 jul. 2017.

Lei ${ }^{\circ}$ Lei $\mathrm{n}^{\circ} 13.483$, de 21 de setembro de 2017. Institui a Taxa de Longo Prazo (TLP); [...]. Diário Oficial da União, Brasília, D.O.U. de 22/09/2017, p. 3.

, Ministério do Esporte. Segundo tempo. Brasília, 2011c. http://www.esporte.gov.br/index.php/institucional/esporte-educacao-lazer-e-inclusaosocial/segundo-tempo.

http://www.esporte.gov.br/arquivos/snelis/segundoTempo/DiretrizesdoProgramaSegund oTempo.pdf. Acesso em: 30 jul. 2017.

Ministério da Saúde. Portaria $\mathrm{n}^{\circ}$ 2.446, de 11 de novembro de 2014. Redefine a Política Nacional de Promoção da Saúde (PNPS). Diário Oficial da União, Brasília, D.O.U. de 11/11/2014, seção 1, p. 68.

FILIPO, Leonardo. Custo dos Jogos Olímpicos do Rio é atualizado e chega a R\$ 41 bilhões. Disponível em: https://globoesporte.globo.com/olimpiadas/noticia/custo-dosjogos-olimpicos-do-rio-e-atualizado-e-chega-a-r-41-bilhoes.ghtml. Acesso em: 13 abr. 2018.

FREY. Klaus. Políticas públicas: um debate conceitual e reflexões referentes à prática da análise de políticas públicas no Brasil. Planejamento e políticas públicas (IPEA), Brasília, v. 21, p. 211-259, jun. 2000. 
IBGE. População brasileira e expectativa de vida. Rio de Janeiro, IBGE, 2017. Disponível em: http://www.ibge.gov.br/apps/populacao/projecao/index.html. Acesso em: 16 jun. 2017.

INEP. Censo escolar 2016. Brasília, Ministério da Educação. Disponível em: http://portal.inep.gov.br/web/guest/resultados-e-resumos. Acesso em: 16 jun. 2017.

MULLER, Pierre; SUREL, Yves. O que é política pública? Trad. Alceu Ravanello Ferraro. Pelotas: Universidade Católica, 2000.

Alceu R. Ferraro. Pelotas: Educat, 2002.

LENZA, Pedro. Direito Constitucional Esquematizado. 20. ed. São Paulo: Saraiva, 2016.

OMS/WHO. Organização Mundial da Saúde. Constituição da Organização Mundial da Saúde (OMS/WHO) - 1946 elaborada em Nova Iorque/EUA. OMS/WHO. Sede em Genebra/Suíça. Disponível em: http://ses.sp.bvs.br/lis/resource/22006\#.WUbqUuvyvIV http://www.direitoshumanos.usp.br/index.php/OMS-Organiza\%C3\%A7\%C3\%A3oMundial-da-Sa\%C3\%BAde/constituicao-da-organizacao-mundial-da-saudeomswho.html. Acesso em: 16 jun. 2017.

ONU. Assembleia Geral das Nações Unidas. DUDH - Declaração Universal dos Direitos Humanos (1948). ONU-Brasil. Disponível em: http://www.onu.org.br/img/2014/09/DUDH.pdf. Acesso em: 16 jun. 2017.

\section{Endereço dos(as) Autores(as):}

Marco Aurélio Paganella

Rua Gomes de Carvalho, 455, ap. 53 - Vila Olímpia

São Paulo - SP - 04.547-001

Endereço eletrônico: marcoapaganella@globo.com

Sílvia Cristina Franco Amaral

Av. Érico Veríssimo, 701

Cidade Universitária "Zeferino Vaz" - Barão Geraldo

Campinas - SP - 13.083-851

Endereço eletrônico: scfa@fef.unicamp.br 